\title{
28 Research Square \\ Surgery in Times of Conflict: Reflection of a Jordanian Surgeon in Afghanistan
}

\section{Ali Al Ebous}

King Hussein Cancer Center

Amal Al-Tabba'

King Hussein Cancer Center https://orcid.org/0000-0003-3460-2686

Mahmoud Ahmed Al Yamani

Al Sairah General hospital

Maysa Al-Hussaini ( $\nabla$ mhussaini@khcc.jo)

Department of Pathology and Laboratory Medicine, 202 Queen Rania Street https://orcid.org/00000001-6392-150X

Notes from the field

Keywords: Surgery, Conflict, Jordan, Afghanistan, Experience

Posted Date: April 1st, 2021

DOI: https://doi.org/10.21203/rs.3.rs-377828/v1

License: (1) (1) This work is licensed under a Creative Commons Attribution 4.0 International License. Read Full License 


\section{Abstract}

In January 2002, the Jordanian military field hospital was established in Mazar-e-Sharif in Afghanistan to provide medical care to many Afghanis. The Jordanian Military represented by the Royal Medical Services (RMS), a leading health authority in Jordan, was responsible for the staffing, operations, and security of the hospital, while the U.S. military offered logistical support, including the delivery of up to 7,500 different medical supplies and training of the Jordanian Special Forces team to maintain security of the field hospital.

In this paper a Jordanian surgeon, who is one of the authors (A.E) shares his experience lasting for 100 days in the Jordanian military field hospital in Afghanistan in 2003 and describes the challenges and strengths/ opportunities of such experience from facilities and resources available to medical staff and surgical treatment provided. In addition, the paper outlines the faced religious, cultural and ethical issues of performing surgery at times of conflict.

The 100-day mission had demonstrated the pivotal role surgeons can play in providing essential care and surgical treatment to civilians at times of conflict. A well-organized mission with the right medical expertise can make a real difference in the lives of others and can overcome many logistical, cultural and ethical barriers faced during such hard times.

\section{Background}

After the 10-year the former Soviet Union invasion (from 1979 to 1989), most of the Western support to Afghanistan was withdrawn. Internal conflicts for domination and the latter inefficient Taliban government lead to the destruction of Afghanistan's infrastructure including the already inadequate health care facilities available, resulting in a poor health care system. After the disposition of the Taliban in 2001 by the United States invasion, NGOs were the main entities delivering health care to the public in Afghanistan including emergency services [1,2].

In 2001, Afghanistan reported one of the poorest health indicators in the world (Table 1) [3]. Infectious diseases, including malaria, measles, acute respiratory infections and diarrheal diseases, in addition to malnutrition, physical and psychological traumas and human right abuses were highly prevalent in the country [4]. 
Table 1

Health Indicators in Afghanistan in 2000 [3].

\begin{tabular}{|ll|}
\hline Health Indicator & \\
\hline Infant mortality (per 1,000 live births) & 165 \\
\hline Under age 5 mortality (per 1,000 live births) & 257 \\
\hline Life expectancy & 41 years \\
\hline Women with antenatal care & $4.6 \%$ \\
\hline Skilled attendant delivery & $6 \%$ \\
\hline
\end{tabular}

In January 2002, the Jordanian military field hospital was established in Mazar-e-Sharif in Afghanistan to provide medical care to many Afghanis. The Jordanian Military represented by the Royal Medical Services (RMS), a leading health authority in Jordan, was responsible for the staffing, operations, and security of the hospital, while the U.S. military offered logistical support, including the delivery of up to 7,500 different medical supplies and training of the Jordanian Special Forces team to maintain security of the field hospital [5].

Since the grand opening of the 50-bed hospital, over 500,000 Afghans was treated with 807,522 patient visits, 7,572 surgeries performed 4,833 admissions and millions of immunizations. The Jordanian hospital offered medical care for the first time for many Afghans and as stated by a US CENTCOM DJ5 "was truly a cornerstone to winning hearts of Afghans"'. This is not surprising, since RMS was ranked as number 1 supporter for the UN \& Humanitarian Missions across Middle East \& North Africa. Over the years, the Jordanian Field Hospitals were positioned in 31 different locations including Afghanistan, Palestine, Liberia, Congo Haiti, Cote D'ivoire, and Egypt to name a few (Figure-1), protecting lives, alleviating hardships and safeguarding dignity of persons/nations [5-7].

In this paper a Jordanian surgeon, who is one of the authors (A.E), shares his experience lasting for 100 days in the Jordanian military field hospital in Afghanistan in 2003 and describes the challenges and strengths/ opportunities of such experience in addition to the faced ethical implications and dilemmas.

\section{Facilities}

The field hospital consisted of two inpatient tents, each consisting of 12-13 beds, in addition to outpatients (Figure-2). The inpatient tents had constantly running generators, which kept power for lights, heat and life-saving machines running. Clean water and meals were provided to patients and their families. The tents were well-equipped medical facility. Ultrasounds, X-Rays, routine laboratory tests (such as Complete Blood Count (CBC) and thyroid function tests) were all available at the field hospital. Nonetheless, pathology services and CT-scan were not available. Such request would be sent to the capital Kabul for processing, which took months for the results to return, forcing doctors to improvise and 
take hard management decisions to provide the best care possible to their knowledge. Medical supplies were always kept in stock including vitamins and other pharmacy supplies.

Although housed in tents, the field hospital was clean with high infection control standards. Zero surgically-related infections rate was reported during this period although major surgeries were performed. The most common surgery was thyroidectomy due to massive goiter secondary to iodine deficiency (Figure-3). Other types of surgery included removal of huge abdominal masses, reconstructive and plastic surgeries (Figure $4 \mathrm{a}-\mathrm{d}$ ) including cleft left, war injuries and amputation, and burn-related wound debridement, resection of gastrointestinal tumors, and disc surgeries. Security measures were in place to ensure the safety of both the Jordanian medical team and to the patients and their families. All of the above-mentioned factors had provided the Afghans' the chance to access high quality, safe and essential surgery.

\section{Medical Staff}

The medical staff was all males and included Jordanian doctors, nurses and some paramedics who had extensive expertise in a variety of fields, including internal medicine, general surgery, primary care, emergency medicine, cardiology, obstetrics and gynecology, pediatrics, dermatology, gastroenterology, rheumatology, orthopedics and urology. In addition to Afghan doctors, community members and paid translators helped facilitate the treatment of patients.

As sad as it is, the field hospital provided a great training opportunity for Afghan doctors and medical staff, as they were guided and trained by Jordanian doctors with extensive medical and surgical expertise. This has successfully contributed to building qualified healthcare workforce in Afghanistan, especially with the witnessed "brain drain" of qualified healthcare workers outside of the country and the lack of reliable local medical training programs at that time.

\section{Religious, Cultural and Ethical Issues}

Although paid translators were always present, language barrier between Jordanian doctors and Afghan patients still existed. The all-male medical staff also presented a challenge as according to Afghan cultural norms only women can provide medical care for other women. The Afghans showed an overall trust of the Jordanian doctors; this probably is due to similar religious beliefs and cultural norms. This has contributed to the unique success of the field hospital compared to many other relief groups with religious affiliations who had previously reported facing major obstacles when it comes to working in Afghanistan [8].

Privacy and confidentiality issues were taken into consideration; nonetheless, the Jordanian surgeon reported that no actual consenting took place before surgeries. There was no medical records for patients or any formal tracking or record-keeping system, which made the surgeon task more challenging from obtaining patients' medical history to providing postoperative care. This issue resulted in interruption of proper care, especially when surgeons are deployed on short missions resulting in participation of several 
surgeons in the treatment of a single patient. Challenges such as low literacy and poverty remained. Very poor roads and lack of transportation system forced patients to walk or use livestock to visit the field hospital from surrounding rural areas.

\section{Conclusion}

The 100-day mission had demonstrated the pivotal role surgeons can play in providing essential care and surgical treatment to civilians at times of conflict. A well-organized mission with the right medical expertise can make a real difference in the lives of others and can overcome many logistical, cultural and ethical barriers faced during such hard times.

\section{Abbreviations}

CBC: Complete Blood Count

RMS: Royal Medical Services

\section{Declarations}

\section{Ethics approval and consent to participate:}

Not applicable

\section{Consent for publication:}

The images used were obtained at the time of the presence of Dr. and Dr. During the mission in Afghanistan for documentation purposes. No consent was obtained at that time. The images are handled in a way that the identity of the participants cannot be revealed. However, if this cannot be accepted, then we can remove the images.

\section{Availability of data and materials:}

The original contributions presented in the study are included in the article/supplementary material, further inquiries can be directed to the corresponding author.

\section{Competing interests:}

The authors declare that they have no competing interests.

\section{Funding:}

No funding.

\section{Authors' contributions:}


AA-E and MA-Y: collection of data, review and approval of final draft, AA-T: literature review, writing the first draft, review and approval of final draft, MA-H: inception of the idea, critical review and editing of the first draft, and final approval.

\section{Acknowledgements:}

Not applicable

\section{References}

1. Saguil A, McCormack MT. Preparing for Afghanistan's medical future. Can Med Assoc J. Can Med Assoc; 2008;178:990.

2. Kondro W. Afghanistan: Outside the comfort zone in a war zone. Can Med Assoc J. Can Med Assoc; 2007;

3. WHO | World Health Organization. WHO Country Cooperation Strategies and Briefs. WHO [Internet]. World Health Organization; 2015 [cited 2019 Sep 3]; Available from: https://www.who.int/countrycooperation/what-who-does/strategies-and-briefs/en/

4. WHO | World Health Organization. WHO | Afghanistan: country profiles [Internet]. WHO. World Health Organization; 2017 [cited 2019 Sep 19]. Available from: https://www.who.int/gho/countries/afg/country_profiles/en/

5. McDorman K. Jordanian-U.S. cooperation brings healing to Afghanistan - Afghanistan | ReliefWeb [Internet]. US Dep. State. 2002 [cited 2019 Sep 5]. Available from: https://reliefweb.int/report/afghanistan/jordanian-us-cooperation-brings-healing-afghanistan

6. Military Medicine Worldwide. Almanac: Jordan, Hashemite Kingdom of Jordan [Internet]. [cited 2019 Sep 5]. Available from: https://military-medicine.com/almanac/69-jordan-hashemite-kingdomof.html

7. Al-Jader K. Managing the medical implications of human catastrophe - Jordan's Global Peace Delegates: Syrian Refugees Crisis. Amman; 2014.

8. Ahmad K. Health and safety of Afghans hangs in the balance. Lancet. Elsevier Science Publishing Company, Inc.; 2001;358:1069-70.

\section{Figures}




\section{RMS - Health Diplomacy}

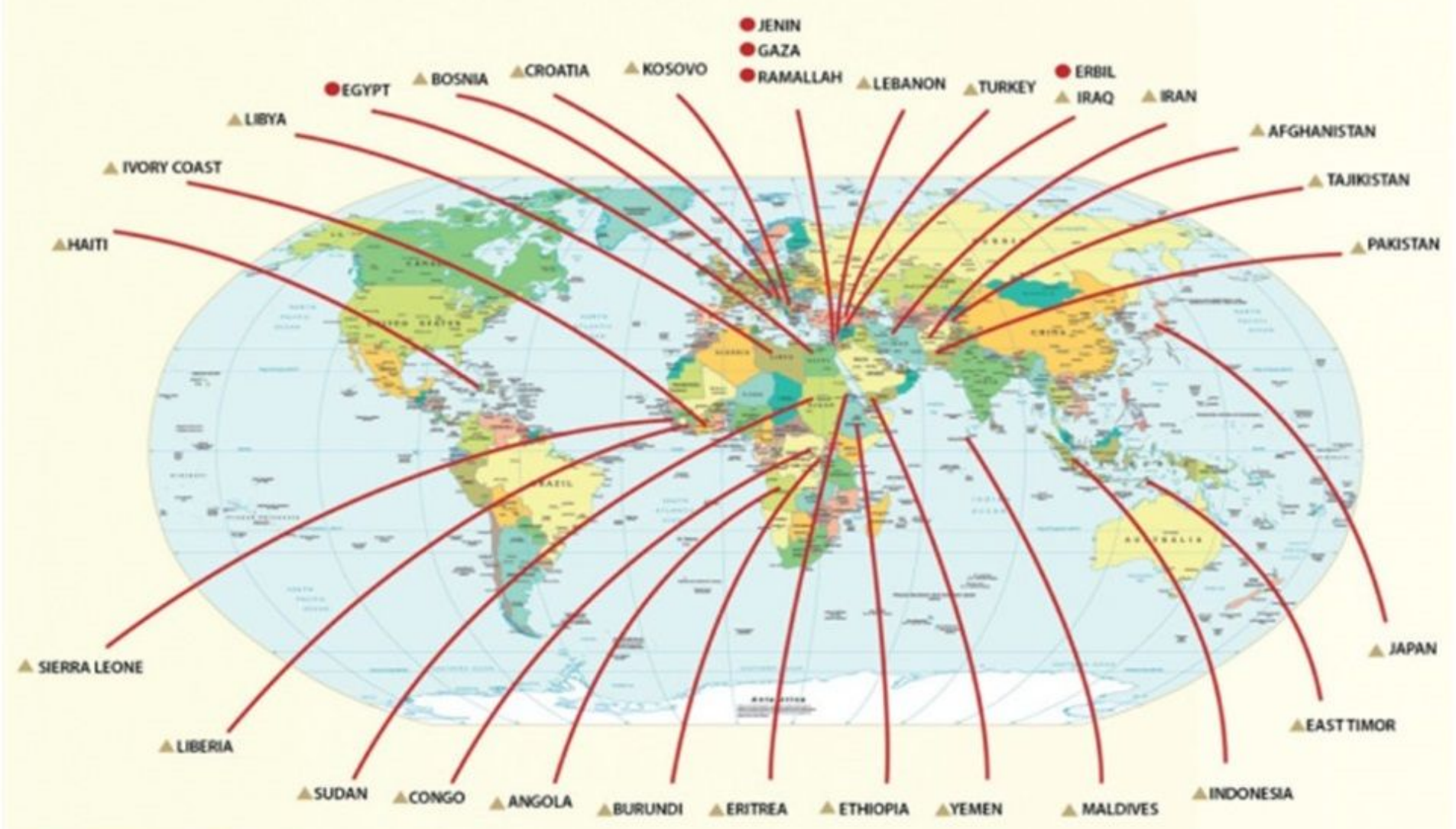

CURhentry actwe Missions

Temorant \& mest Mossions

\section{Figure 1}

The Jordanian Royal Medical Services (RMS) field hospitals deployed to 31 different locations. Note: The designations employed and the presentation of the material on this map do not imply the expression of any opinion whatsoever on the part of Research Square concerning the legal status of any country, territory, city or area or of its authorities, or concerning the delimitation of its frontiers or boundaries. This map has been provided by the authors. 


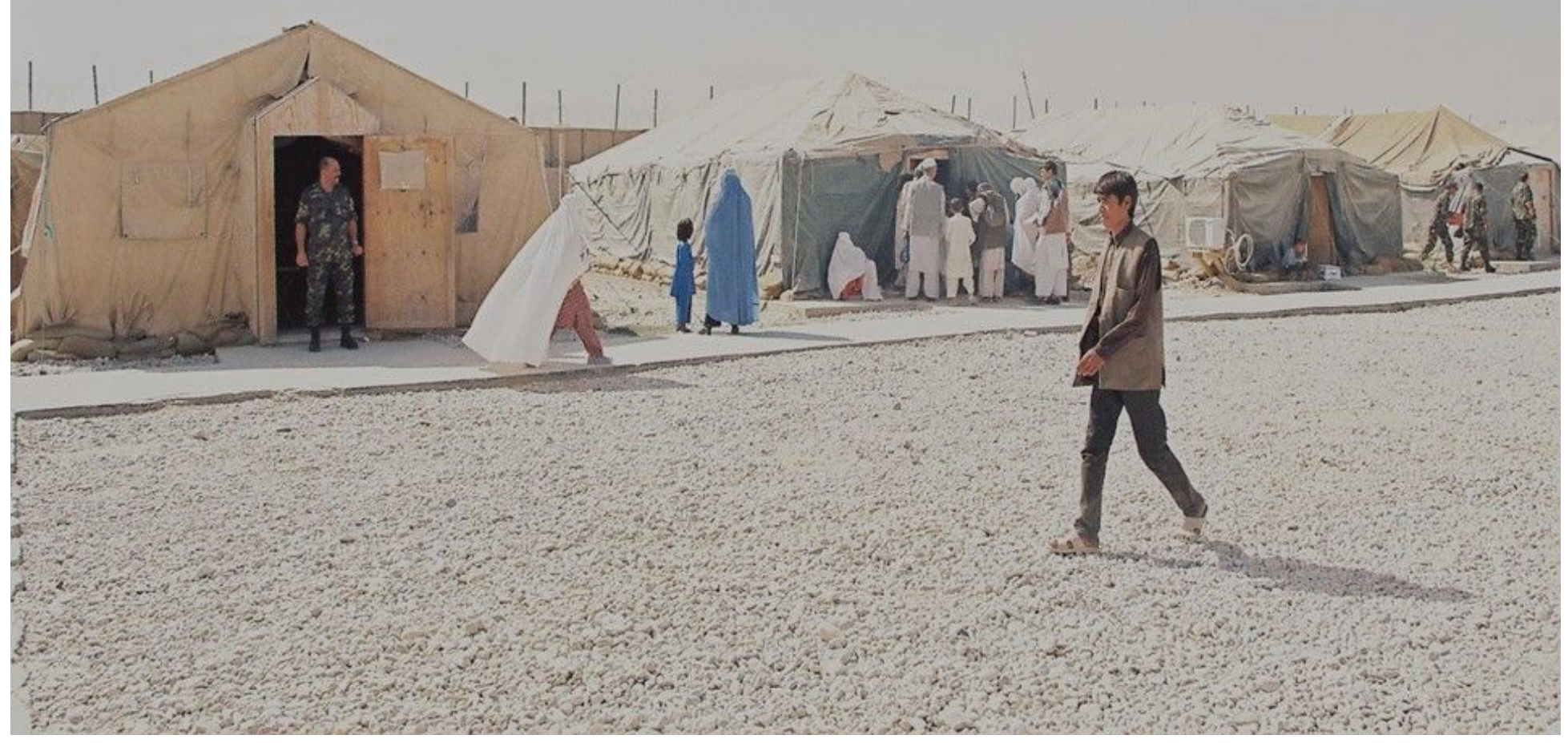

Figure 2

An outer view of the tents used as outpatient clinic by the RMS 


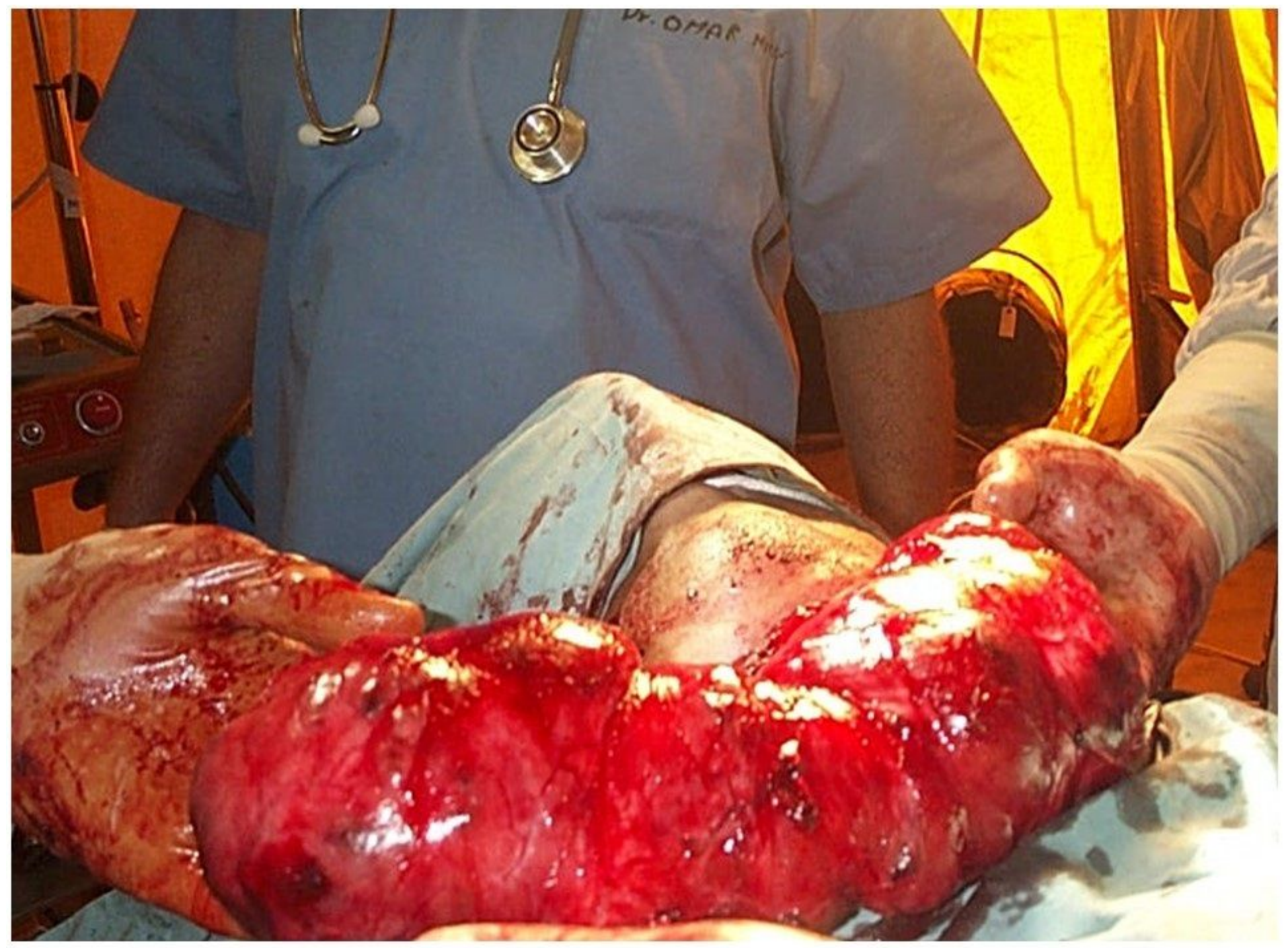

Figure 3

A surgically resected thyroid gland for a case of a massive goiter in one of the patients. 


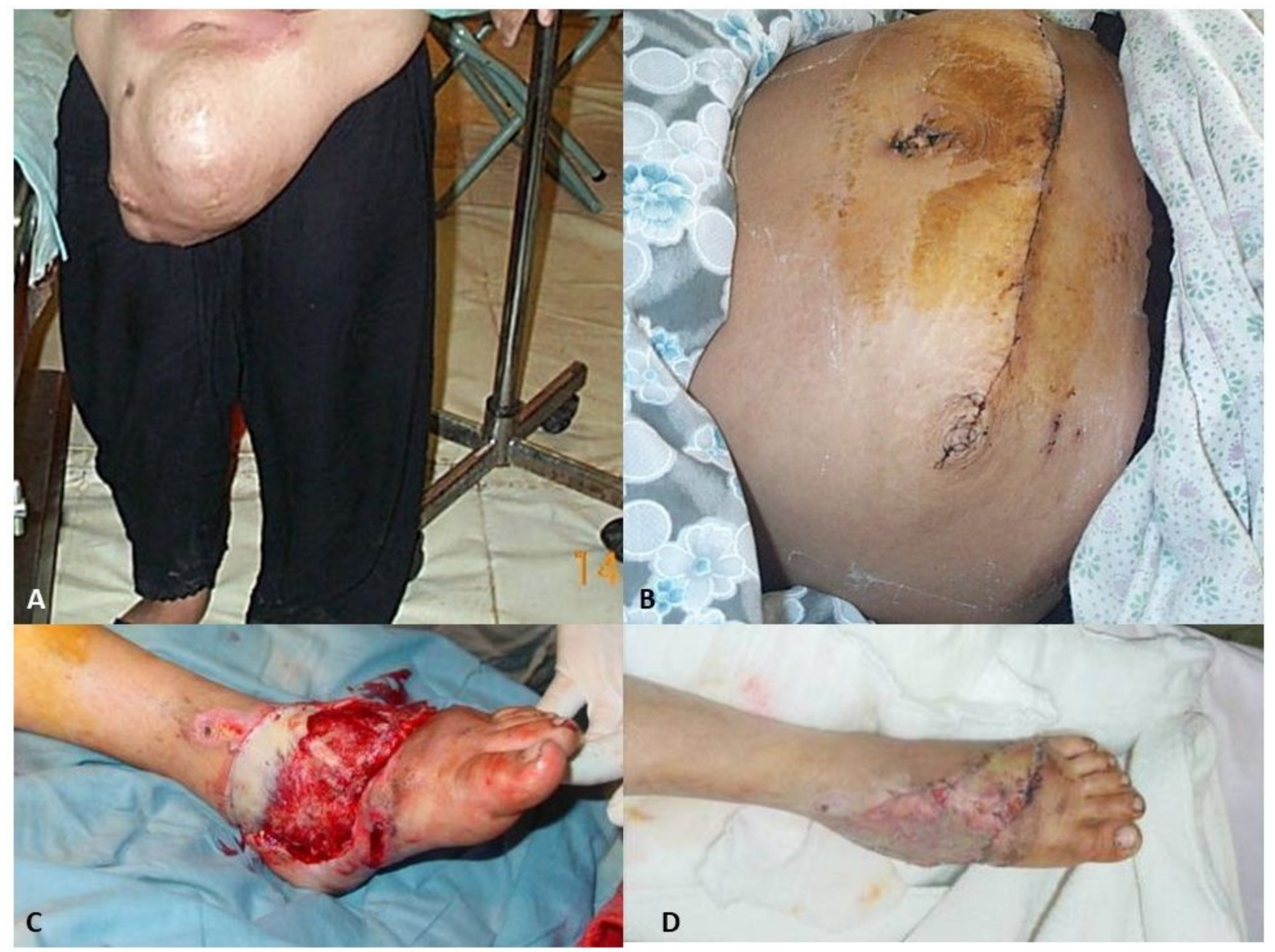

Figure 4

Two examples of cases for which $A$ and $B$; resection of abdominal mass was performed for a young female patient following delivery. $C$ and $D$; debridement and healing of an open wound in the left leg. (A and $\mathrm{C}$; before and $\mathrm{B}$ and $\mathrm{D}$; after surgery). 